\title{
The Mathematical Model for searching the Shortest Route for Tuberculosis Patients with the help of Dijkstra's Algorithm
}

\begin{abstract}
Muhammad Shahid ${ }^{1}$, Hammad Khawar ${ }^{1}$, Muhammad Ayoub Kamal ${ }^{2,3}$
Abstract:

In this research paper, we have studied TB (Tuberculosis) patients who come from different traffic routes in order to seek medical help and treatment in Karachi, Sindh, Pakistan. Through this scholarly article, we have focused on the transportation problems of the TB patients. These TB patients can travel on the paths having minimum distance as found out in this paper using Dijkstra's Algorithm.

People hope that they have better treatment opportunities and financial medical relief in the government and private hospitals in Karachi. People belonging to the poor or lower and middle classes approach government hospitals adequately as private hospitals are expensive. Among them, Nazimabad Chest Hospital for TB patients (under the supervision of Dow University of Health Sciences) provides good medical treatments for the similar medical issues and it is renowned for its high quality treatment of TB patients. The hospital is located inside Government Hospital Nazimabad (under the control of Dow University), Karachi. TB Patients have to visit the hospital on weekly basis from their homes and residences. They use several combinations of traffic routes to reach the hospital as these patients live in different areas like, Malir Cantt, Safari Park, Hassan Square, North-Nazimabad, North Karachi, Gulshan-e-Iqbal, etc. In this scholarly article, research has been made to locate the shortest route for the convenience for these TB patients by making a mathematical model using the method of Dijkstra's algorithm. Our result shows that a TB patient residing in Malir Cantt should follow the route comprising of Malir Cantt, Safari Park, Laiquatabad and Nazimabad Chest Hospital for TB patients, without changing the sequence, in order to make the traveling more effective in terms of the transportation cost or fare, distance, reduced suffering, time, etc.
\end{abstract}

Keywords: Dijkstra's Algorithm; Node 1 - Malir Cantt; Node 5 - Nazimabad Chest Hospital; Dow University; Karachi; Permanent Label; TB; Tuberculosis

\section{Introduction}

Karachi city is a mega city of Pakistan. Nazimabad Institute of Chest Diseases is giving medical services to TB (Tuberculosis) patients in Karachi. The said institute is working under the supervision of Dow University of Health Sciences, Karachi. It is located inside Government Hospital, Nazimabad. The said hospital is the only hospital equipped with latest facilities, competent and qualified staff. WHO (World Health Organization) also honored it as a centre of excellence for TB treatment. These paramedical staff and qualified doctors are

\footnotetext{
${ }^{1}$ Baqai Institute of Information Technology, Baqai Medical University, Pakistan.

${ }^{2}$ Malaysian Institute of Information Technology, Universiti of Kuala Lumpur, Kuala

Lumpur, Malaysia.

${ }^{3}$ Institute of Business Management (IoBM), Korangi Creek, Pakistan.

Corresponding Author: muhammad.ayoub@s.unikl.edu.my
} 
Muhammad Shahid (et al.), The Mathematical Model for searching the Shortest Route for Tuberculosis Patients with the help of Dijkstra's Algorithm

(рp. $41-48)$

available for people who are living at various locations in Karachi like, Gulshan-e-Iqbal, Safari Park, Malir Cantt, North Karachi, North Nazimabad, etc. Patients living in different areas are encountering problems in getting medical treatment from the Nazimabad Chest Hospital for TB patients (under the supervision of Dow University). In order to get the proper medical treatment from the hospital, they spend a lot of time, money as well as energy in travelling back and forth between the hospital and their residential areas.

Tuberculosis is a disease which usually destroys the lungs. The problem with this disease is that it is has the ability to spread in the body and affect other organs. Another problem with TB is that it can spread slowly through air. It is known that bacteria named Mycobacterium is responsible for this disease. This disease gradually and painfully kills the sick patient if it is not taken seriously. This is evident from the fact that approximately about a million deaths are caused by TB in the world. Fortunately, in this modern era of health sciences, a TB patient gets cured after getting proper medical attention and treatment [1]
In this paper, research has been done to find out the shortest traffic route in order to provide accessibility and convenience to the needy and poor TB patients. With the help of the application of a mathematical model using Dijkstra's Algorithm, efforts have been made to track down the shortest route from Malir Cantt to Nazimabad Chest Hospital for TB patients (running under the management of Dow University) [2][3][4][5].

To accomplish the objective, the City Government, Highway Authority and interrelated departments were approached to get the data necessary for the determination of alternate routes. Different important locations inside Karachi have been chosen and labeled as nodes. The information created from the data consisting of the nodes and the distances between them is represented by Table 1 . The names of the physical location represented by each node have been shortened so that the process becomes more intuitive while keeping the accuracy of the results unaffected $[6][7][8]$.

These locations are chosen as nodes due to the fact that TB patients frequently travel from and through these locations to reach the hospital. These nodes are taken by us for our research study also because of the fact that while traveling, these TB patients constantly face problems in terms of money, time and energy as there exists several combinations of possible traffic routes among these chosen nodes and TB patients do not have

Table 1: Nodes, corresponding numbers, locations and distances among them

\begin{tabular}{|c|c|l|c|c|}
\hline $\begin{array}{c}\text { Starting } \\
\text { Location name }\end{array}$ & $\begin{array}{c}\text { Corresponding } \\
\text { Node No. }\end{array}$ & \multicolumn{1}{|c|}{ Ending Location name } & $\begin{array}{c}\text { Corresponding } \\
\text { Node No. }\end{array}$ & $\begin{array}{c}\text { Distance } \\
(\mathbf{k m})\end{array}$ \\
\hline Malir Cantt & 1 & Safari Park & 2 & 8 \\
\hline Safari Park & 2 & Liaquatabad & 4 & 9 \\
\hline $\begin{array}{c}\text { Gulshan } \\
\text { Chowrangi }\end{array}$ & 3 & Safari Park & 2 & 3 \\
\hline Malir Cantt & 1 & Gulshan Chowrangi & 3 & 12 \\
\hline $\begin{array}{c}\text { Gulshan } \\
\text { Chowrangi }\end{array}$ & 3 & Liaquatabad & 4 & 7 \\
\hline $\begin{array}{c}\text { Gulshan } \\
\text { Chowrangi }\end{array}$ & 3 & $\begin{array}{l}\text { Nazimabad Chest Hospital for } \\
\text { TB patients }\end{array}$ & 5 & 13 \\
\hline
\end{tabular}


Muhammad Shahid (et al.), The Mathematical Model for searching the Shortest Route for Tuberculosis Patients with the help of Dijkstra's Algorithm

information about the shortest possible route that they should follow in order to reduce their sufferings as well as increase their efficiency of medical treatment.

To find the shortest route from Malir Cantt to Nazimabad Chest Hospital for TB patients (under the supervision of Dow University), Dijkstra's algorithm showed itself to be useful in this mathematical model. Dijkstra's algorithm has been used to calculate the shortest route / path between the source node and every other node in the network [9][10][13]. Dijkstra's Algorithm has been applied in a general manner so that it allows determining the shortest route / path between any two nodes in the network [14][15].

Our scientific study is important and effective with respect TB patients traveling to seek medical help. Even $1 \mathrm{~km}$ can increase the chances of saving lives of TB patients. Furthermore, our finding of the shortest route will reduce financial burden on the TB patients with respect to the transportation cost in this mega city of Pakistan. Furthermore, our research work will also help to reduce the suffering time of seriously infected TB patients by reducing the traveling distance, even if it is only $1 \mathrm{~km}$.

\section{Methodology And Modeling}

In this method, we applied this Dijkstra's algorithm to judge the shortest path. Different assumptions and notations have been used in the paper for applying Dijkstra's algorithm on the problem. Dijkstra's algorithm is limited to work on positively valued metrics only. Here, every metric represents a spatial distance (1 dimensional quantity) among the nodes. All distances are measured in kilometers. Further notations are discussed below.

\subsection{Notations}

Let $\mathrm{u}_{\mathrm{i}}$ be the shortest distance from source Node 1 to Node $i$. Let $d_{\mathrm{ij}} \geq 0$ where $d_{\mathrm{ij}}$ defines the arc length $(i, j)$. The label of the immediate successor of node $i$ i.e. node $j$, can be defined by the algorithm by (1): $\left[u_{\mathrm{j}}, i\right]=\left[u_{\mathrm{i}}+d_{\mathrm{ij}}, i\right], d_{\mathrm{ij}} \geq 0$

In the path finding process, the label $[0,-$ -] given to the starting node indicates that the node has no predecessor.

\subsection{Permanent and Temporary Labels}

Node labels in Dijkstra's algorithm are of two types i.e. Temporary and Permanent. A temporary label is modified if a shorter route to a node can be found. If no better route can be found, the status of the temporary label is changed to permanent. The status of the labels are changed according to Dijkstra's algorithm and also verified by open source program code later on in this paper.

\subsection{Sequence of Operation}

The computation by the algorithm is carried out using two major steps.

\subsection{Step No. 1}

In the first step, consider the starting point node 1 . We apply permanent label $[0,-$ ] on node 1 . We also let $i=1$.

\subsection{Step No. 2 (a)}

In the second step, evaluate the temporary labels $\left[u_{\mathrm{i}}+d_{\mathrm{ij}}, i\right]$ for every node $j$ that can be reached from node $i$, provided $j$ is not permanently labeled. If node $j$ is previously labeled with $\left[u_{\mathrm{j}}, k\right]$ via another node $k$ and if $u_{\mathrm{i}}+d_{\mathrm{ij}}<u_{\mathrm{j}}$ then replace $\left[u_{\mathrm{j}}, k\right]$ with $\left[u_{\mathrm{i}}+d_{\mathrm{ij}}\right.$, i].

\subsection{Step No. 2 (b)}

If all the nodes have permanent labels then stop the computation. Otherwise, select that label $\left[u_{\mathrm{r}}, s\right]$ among all the temporary labels that has the shortest distance i.e. for any temporary Node $r$, its reaching distance $u_{\mathrm{r}}$ is the smallest one. Set $i=r$ and repeat Step no. 1. 
Muhammad Shahid (et al.), The Mathematical Model for searching the Shortest Route for Tuberculosis Patients with the help of Dijkstra's Algorithm

(pp. $41-48)$

\subsection{Network Diagram and Table}

Keeping in view the present scenario, the chosen nodes from 1 through 5 are outlined in Table 2 and the created network diagram is shown in Fig. 1.

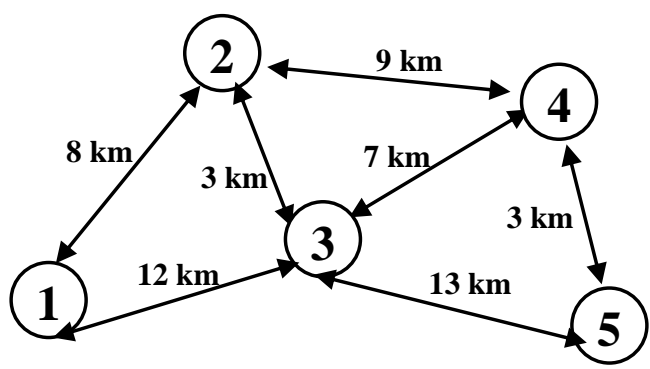

Fig. 1. Network diagram of the scenario.

Table 2: Summary Table of Node No. alloted against each location

\begin{tabular}{|c|l|}
\hline $\begin{array}{c}\text { Node } \\
\text { No. }\end{array}$ & \multicolumn{1}{|c|}{$\begin{array}{c}\text { Map Location name shortened for } \\
\text { Node Name }\end{array}$} \\
\hline 1 & Malir Cantonment (or simply, Cantt) \\
\hline 2 & Karachi Safari (or simply, Safari) Park \\
\hline 3 & $\begin{array}{l}\text { Gulshan-e-Iqbal (or simply, Gulshan) } \\
\text { Chowrangi }\end{array}$ \\
\hline 4 & $\begin{array}{l}\text { Liaquatabad (formerly, Lalukhet or Laloo } \\
\text { Khait) }\end{array}$ \\
\hline 5 & $\begin{array}{l}\text { Nazimabad Chest Hospital for TB patients } \\
\text { under the supervision of Dow University of } \\
\text { Health Sciences, Karachi (or simply, } \\
\text { Nazimabad) }\end{array}$ \\
\hline
\end{tabular}

\subsection{Iteration no. 0}

In this iteration no. 0 , we allocate the permanent label $[0,-]$ to node 1 due to the fact that there is no preceding node.

\subsection{Iteration no. 1}

In this iteration no. 1, Nodes 2 and 3 can be reached from the node 1 (labeled as permanent, previously). Thus, the labeling (temporary and permanent) for these nodes are shown in the Table 3.
Table 3: Node Labels at Iteration no. 1

\begin{tabular}{|c|l|c|}
\hline $\begin{array}{c}\text { Node } \\
\text { No. }\end{array}$ & \multicolumn{1}{|c|}{ Label } & \multicolumn{1}{|c|}{ Status } \\
\hline 1 & {$[0,-]$} & Permanent \\
\hline 2 & {$[0+8,1]=[8,1]$} & Temporary \\
\hline 3 & {$[0+12,1]=[12,1]$} & Temporary \\
\hline
\end{tabular}

From two temporary labels $[8,1]$ and $[12$, 1 ], the yield of Node 2 is smaller for $u_{2}=8$. Thus, the status of Node 2 is changed to permanent.

\subsection{Iteration no. 2}

In this iteration no. 2 , we can reach Nodes 3 and 4 from Node 2 (labeled as permanent, previously). Thus, the labeling (temporary and permanent) for these nodes are shown in the Table 4.

Table 4: Node Labels at Iteration no. 2

\begin{tabular}{|c|l|c|}
\hline $\begin{array}{c}\text { Node } \\
\text { No. }\end{array}$ & \multicolumn{1}{|c|}{ Label } & Status \\
\hline 1 & {$[0,-]$} & Permanent \\
\hline 2 & {$[8,1]$} & Permanent \\
\hline 3 & {$[12,1],[8+3,2]=[11,2]$} & Temporary \\
\hline 4 & {$[8+9,2]=[17,2]$} & Temporary \\
\hline
\end{tabular}

From the temporary labels $[12,1]$ and $[11,2]$, the yield of Node 3 is smaller for $u_{3}=$ 11. Thus, the status of Node 3 changes to permanent.

\subsection{Iteration no. 3}

Nodes 4 and 5 can be reached from Node 3 (labeled as permanent, previously). Thus, the list of labeled nodes (temporary and permanent) becomes as shown in the Table 5 . 
Muhammad Shahid (et al.), The Mathematical Model for searching the Shortest Route for Tuberculosis Patients with the help of Dijkstra's Algorithm

(pp. $41-48)$

Table 5: Node Labels at Iteration no. 3

\begin{tabular}{|c|l|c|}
\hline $\begin{array}{c}\text { Node } \\
\text { No. }\end{array}$ & \multicolumn{1}{|c|}{ Label } & \multicolumn{1}{|c|}{ Status } \\
\hline 1 & {$[0,-]$} & Permanent \\
\hline 2 & {$[8,1]$} & Permanent \\
\hline 3 & {$[12,1],[11,2]$} & Permanent \\
\hline 4 & {$[17,2],[12+7,3]=[19,3]$} & Temporary \\
\hline 5 & {$[12+13,3]=[25,3]$} & Temporary \\
\hline
\end{tabular}

From the temporary labels $[17,2]$ and $[19,3]$, the shorter distance exists for Node 4 when $u_{4}=17$. Thus, the status of Node 4 is changed to permanent.

\subsection{Iteration no. 4}

Node 5 can be accessed from Node 3 as seen previously. The label list gets updated as shown in the Table 6 . The rejected and accepted labels along the iteration cycles are shown in Fig. 2.

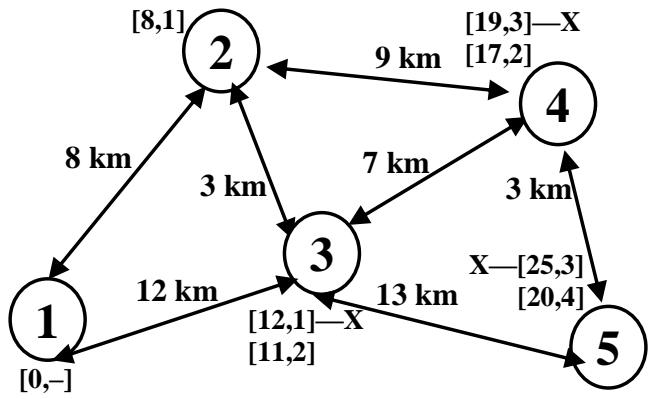

Fig. 2.Updated Network diagram of the scenario

Table 6: Node Labels at Iteration no. 4

\begin{tabular}{|c|l|l|}
\hline $\begin{array}{c}\text { Node } \\
\text { No. }\end{array}$ & \multicolumn{1}{|c|}{ Label } & \multicolumn{1}{|c|}{ Status } \\
\hline 1 & {$[0,-]$} & Permanent \\
\hline 2 & {$[8,1]$} & Permanent \\
\hline 3 & {$[12,1],[11,2]$} & Permanent \\
\hline 4 & {$[17,2],[19,3]$} & Permanent \\
\hline 5 & {$[25,3],[17+3,4]=[20,4]$} & Temporary \\
\hline
\end{tabular}

Node 5 can also be accessed from Node 4 with temporary label $[20,4]$ as shown in Table 6 . Node 5 is already labeled as [25, 3]. Since the label [20, 4] gives a shorter distance, the label at the Node 5 changes its state to permanent with distance $u_{5}=20$.

\subsection{Completion of the computation}

Now, all the nodes are permanently labeled and the algorithm's computation has completed successfully. For any Node w, the shortest distance from Node 1 to Node w computed by the algorithm in our scenario at its different iterations can be summarized in the Table 7.

Table 7: Shortest Distance per Iteration no.

\begin{tabular}{|c|c|c|}
\hline $\begin{array}{c}\text { Iteration } \\
\text { No. }\end{array}$ & $\begin{array}{c}\text { Destination } \\
\text { node, } \boldsymbol{w}\end{array}$ & $\begin{array}{c}\text { Shortest } \\
\text { distance, } \boldsymbol{u}_{\mathbf{w}} \\
(\mathbf{k m})\end{array}$ \\
\hline 0 & 1 & 0 \\
\hline 1 & 2 & 8 \\
\hline 2 & 3 & 11 \\
\hline 3 & 4 & 17 \\
\hline 4 & 5 & 20 \\
\hline
\end{tabular}

The shortest route between Malir Cantt and Nazimabad Chest Hospital for TB patients (under the supervision of Dow University of Health Sciences, Karachi) can be easily seen if we consider destination Node 5 and then follow the nodes in reverse direction using the information given by the permanent labels.

The following sequence establishes the shortest path from Node 1 to Node 5:

Sequence 1. Shortest possible traffic route sequence

$$
(5) \rightarrow[20,4] \rightarrow(4) \rightarrow[17,2] \rightarrow(2) \rightarrow[8,1] \rightarrow(1)
$$

In Sequence 1, the right headed arrow " $\rightarrow$ " represents the tracking direction of the nodes from tail to head of the arrow. In the sequence, " $(w)$ " represents Node $w$ and " $[u$ $w, k]$ " represents the shortest distance $u_{\mathrm{w}}$ 
Muhammad Shahid (et al.), The Mathematical Model for searching the Shortest Route for Tuberculosis Patients with the help of Dijkstra's Algorithm

(рp. $41-48)$

between Node $w$ and Node 1 if TB patients come on the physical location represented by Node $w$ from the physical location represented by the immediate Node $k$. Thus, the desired route to follow is shown in Sequence 2:

Sequence 2. Shortest possible route's nodes sequence

Node $1 \rightarrow$ Node $2 \rightarrow$ Node $4 \rightarrow$ Node 5

Hence, the shortest route between Nazimabad Chest Hospital for TB patients and Malir Cantt is found out to be equal to 20 kilometers only.

\subsection{Results and Discussion}

The shortest distance from Node 1 (Malir Cantt) to Node 5 (Nazimabad Chest Hospital for TB patients, working under the supervision of Dow University of Medical Sciences, Karachi) has been evaluated using the method of Dijkstra's algorithm and is equal to $20 \mathrm{~km}$. The exact result is also achieved from iteration no. 4 as shown in the Table 8.

Table 8: Node Label acceptance

\begin{tabular}{|c|c|c|}
\hline $\begin{array}{c}\text { Iteration } \\
\text { No. }\end{array}$ & $\begin{array}{c}\text { Accepted } \\
\text { Label }\end{array}$ & Rejected Label \\
\hline 1 & {$[0,-]$} & - \\
\hline 2 & {$[8,1]$} & - \\
\hline 3 & {$[11,2]$} & {$[13,1]$} \\
\hline 4 & {$[17,2]$} & {$[19,3]$} \\
\hline 5 & {$[20,4]$} & {$[25,3]$} \\
\hline
\end{tabular}

The shortest route possible between nodes 1 and 5 has been determined with the help of the Sequence 1 i.e.

$$
(5) \rightarrow[20,4] \rightarrow(4) \rightarrow[17,2] \rightarrow(2) \rightarrow[8,1] \rightarrow(1)
$$

Thus, the desired route nodes and sequence fond out to be Sequence 2 i.e.

Node $1 \rightarrow$ Node $2 \rightarrow$ Node $4 \rightarrow$ Node 5

The said route's length is found out to be of $20 \mathrm{~km}$ only.
The result was also verified by writing a computer program code of Dijkstra Algorithm in Python computer programming language using different free online resources like, [16] and [17]. The output of the Python code in Fig. 3 is same as listed in Table 7 or the accepted labels listed in Table 8. The code was made on Python version 3.4.4 with online documentation found at [19]. It was executed using IDLE (Integrated DeveLopment Environment) version 3.4.4 with online documentation found at [18].

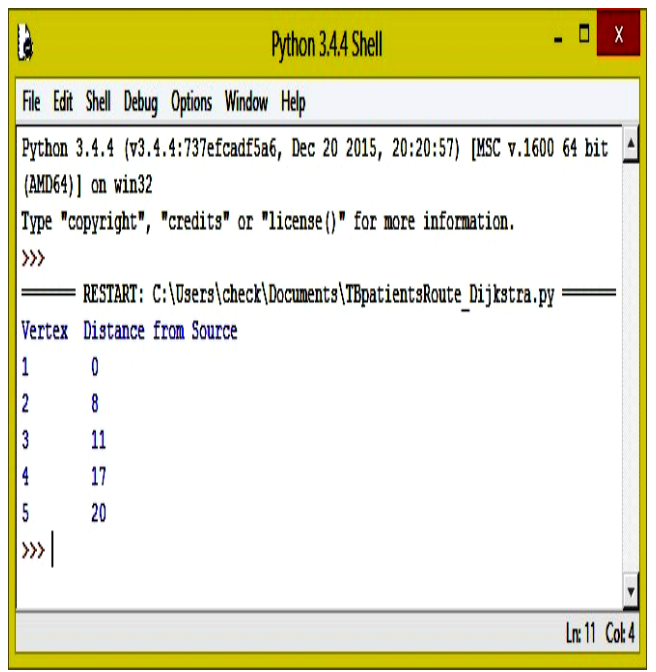

Fig. 3. Calculations of distances verified via Python

The dataset used in this research work consists of real values taken from Karachi city so this study is applicable to Karachi city only. Furthermore, the data is taken for patients residing in Malir Cantt area of Karachi and the corresponding location is referred to as the source node in this paper. The patients are traveling and trying to reach the Nazimabad TB centre of Karachi and the corresponding location is referred to as the destination node in our study. The source node will change if a patient resides in any other area of Karachi and the shortest path will vary accordingly. For example, for a patient residing at Saddar area of Karachi, the shortest path will be calculated between the patient's residential area (Saddar) and 
Muhammad Shahid (et al.), The Mathematical Model for searching the Shortest Route for Tuberculosis Patients with the help of Dijkstra's Algorithm

(pp. $41-48)$

Nazimabad TB centre of Karachi. There will be no change in the methodology and the source code of Python programming language used in our research work other than the corresponding dataset. The methodology presented in this scholarly article can also be adopted to find the shortest path from a location to any other specific hospital within any city of Pakistan using the corresponding dataset. Similarly, our methodology can also be used to find the shortest distance from a location to any other important destination in a city such as, rescue camps, amusement parks, academic institutions, etc. For example, the shortest path for an employee of IBA Sukkar travelling from his/her residential area to IBA Sukkar can also be found out using our methodology, the programming code and corresponding dataset.

\section{Conclusion}

Nazimabad Chest Hospital for TB patients (running under the supervision of Dow Medical University of Health Sciences, Karachi) from different areas outside the city of Karachi, the shortest route has been found between Malir Cantt and Nazimabad Chest Hospital within Karachi, a mega city of Pakistan. The said route is found out to be 20 $\mathrm{km}$ in length and this finding has been done with the help of Dijkstra's algorithm. The said route consists of Nodes 1, 2, 4 and 5. TB patients coming from Malir Cantt have to follow the nodes in the order given below to get advantage of the said route:

Malir Cantt $\rightarrow$ Safari Park $\rightarrow$ Laiquatabad $\rightarrow$ Nazimabad Chest Hospital for TB patients (under the supervision of Dow University of Health Sciences, Karachi).

In order to reach the TB hospital, the said route is found out to be the shortest traffic route that exists among all other traffic routes formed by different combinations of these nodes. The distance traveled by the person on the said route will be only $20 \mathrm{~km}$. The result was also verified by using Python programming language.
The advantage of following the suggested route sequence includes reduced transportation cost that is significant for the TB patients with financial problems, increased chances of saving seriously infected TB patients, decreased amount of suffering time by TB patients due to lessened traveling time, etc.

\section{REFERENCES}

[1] Forum of International Respiratory Societies. "The Global Impact of Respiratory Disease", Second Edition. Sheffield, European Respiratory Society, 2017.

[2] Hillier, Frederick S. "Introduction to operations research", Tata McGraw-Hill Education, 2012.

[3] Taha, Hamdy A. "Operations research: an introduction", Vol. 790. Upper Saddle River, NJ, USA: Pearson/Prentice Hall, 2011.

[4] Morse, Philip McCord, George E. Kimball, and Saul I. Gass. "Methods of operations research", Courier Corporation, 2003.

[5] Giordano, Frank, William P. Fox, and Steven Horton. "A first course in mathematical modeling", Nelson Education, 2013.

[6] Eiselt, Horst A., and Carl-Louis Sandblom. "Operations research: A model-based approach", Springer Science \& Business Media, 2012.

[7] Zaric, Gregory S., ed. "Operations research and health care policy", New York: Springer, 2013.

[8] Winston, Wayne L., and Jeffrey B. Goldberg. "Operations research: applications and algorithms", Vol. 3. Belmont eCalif Calif: Thomson/Brooks/Cole, 2004.

[9] Milburn, Ashlea Bennett. "Operations research applications in home healthcare", In Handbook of Healthcare System Scheduling, pp. 281-302. Springer, Boston, MA, 2012.

[10] Kahraman, Cengiz, and Y. Ilker Topcu, eds. "Operations research applications in health care management", Springer International Publishing, 2018.

[11] Daellenbach, Hans G., John A. George, and Donald C. McNickle. "Introduction to operations research techniques", Boston: Allyn and Bacon, 1978.

[12] Srinivasan, G. "Operations Research: principles and applications", PHI Learning Pvt. Ltd., 2017.

[13] Polgar, Stephen, and Shane A. Thomas. "Introduction to Research in the Health 
Muhammad Shahid (et al.), The Mathematical Model for searching the Shortest Route for Tuberculosis Patients with the help of Dijkstra's Algorithm (pp. $41-48)$

Sciences E-Book", Elsevier Health Sciences, 2011.

[14] Levitin, Anany. "Introduction to the design \& analysis of algorithms", Boston: Pearson, 2012.

[15] Burghes, David N., and Alistair D. Wood. "Mathematical models in the social, management and life sciences", No. HD 30.25. B87. 1980.

[16] "Dijsktra's Algorithm". 2020. Geeksforgeeks. https://www.geeksforgeeks.org/dijkstrasshortest-path-algorithm-greedy-algo-7/.
[17] "Dijkstra Visualization". 2020. Cs.Usfca.Edu. https://www.cs.usfca.edu/ galles/visualizatio n/Dijkstra.html.

[18] "IDLE - Python 3.9.1 Documentation". 2020. Docs.Python.Org.

https://docs.python.org/3/library/idle.html\#

[19] "Overview - Python 3.4.4 Documentation". 2020. Docs.Python.Org.

https://docs.python.org/release/3.4.4/. 